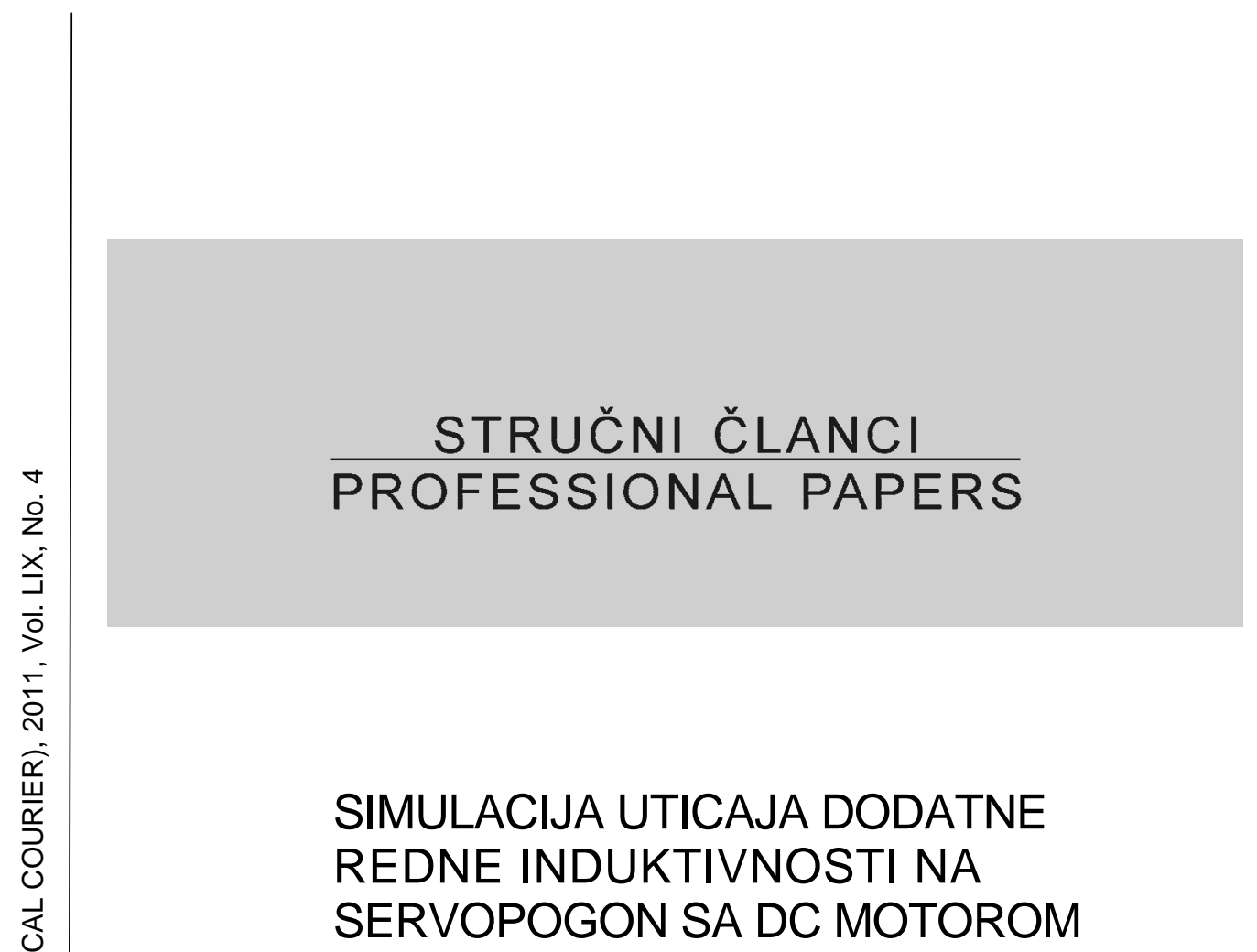

Viličić B. Aleksandar, Jezdimirović M. Mirko, Ministarstvo odbrane Republike Srbije, Vojnotehnički institut, Beograd

OBLAST: elektrotehnika (automatika i upravljanje)

Sažetak:

U ovom radu prikazana je simulacija električnog servopogona sa digitalnim regulatorom. Sistem je simuliran u alatu za simulaciju programskog paketa LabView. Simulirane su identifikovane prenosne funkcije realnog sistema (prenosne funkcija motora, davača struje $i$ ugaone brzine), kao i nelinearnosti motora i reduktora.

Key words: digitalni servosistem, digitalni regulator, upravljanje, redna induktivnost, automatsko upravljanje.

\title{
Uvod
}

Jpravljanje jednosmernim servomotorima sa četkicama (DC) koji imaju malu unutrašnju induktivnost može biti problem. Naime, posledica njihove male induktivnosti je velika brzina promene rotorske struje, kao odziv na primenjeni napon. U slučaju upravljanja impulsno širinski modulisanim signalom (PWM-Pulse Width Modulation) ne sme se dozvoliti drastična promena struje rotora u toku jedne PWM periode. Dosadašnja primenjena istraživanja su pokazala da ukoliko bi se dozvolio veliki porast vrednosti struje u PWM periodi došlo bi do oscilatornog odziva strujne petlje. Ovaj problem može se rešiti povećavanjem učestanosti PWM signala (smanjenje periode). Kao posledica povećane učestanosti prekidačkog signala javlja se povećana disipacija prekidačkih tranzistora u H mostu. Zato se problem re- 
šava dodavanjem induktivnosti na red sa motorom. Posledica dodatne induktivnosti i njene konačne unutrašnje otpornosti je i promena električne vremenske konstante motora.

Tema rada je upotreba novih programskih paketa za analizu simulacionog podešavanja digitalnog regulatora u uslovima različite dodate induktivnosti i uticaj različitih matematičkih simulacionih modela na podešavanje parametara regulatora. $U$ radu je opisan električni servo- sistem sa digitalnim regulatorom za pokretanje modularne turele (obrtna platforma) po azimutu. Dat je matematički model digitalnog servosistema. U programskom paketu LabView, odnosno njegovom setu alatki (toolkit) za simulaciju, izvršena je simulacija konkretnog brzinskog servosistema. S obzirom na to da simulacioni program pruža velike mogućnosti, model motora sa reduktorom simuliran je kao linearni sistem, dok su odabirači i regulatori koji se realizuju programski u mikrokontroleru simulirani kao diskretni elementi servo sistema. Regulatori su podešeni za različite vrednosti redne induktivnosti. Sa ovako podešenim parametrima regulatora snimani su i poređeni odzivi modela simuliranog sistema. Model sistema je simuliran sa zanemarenom električnom vremenskom konstantom i bez zanemarivanja električne vremenske konstante. Izvršeno je snimanje karakteristika servosistema, obrada dobijenih rezultata i poređenje rezultata različitih simuliranih modela za različite vrednosti induktivnosti.

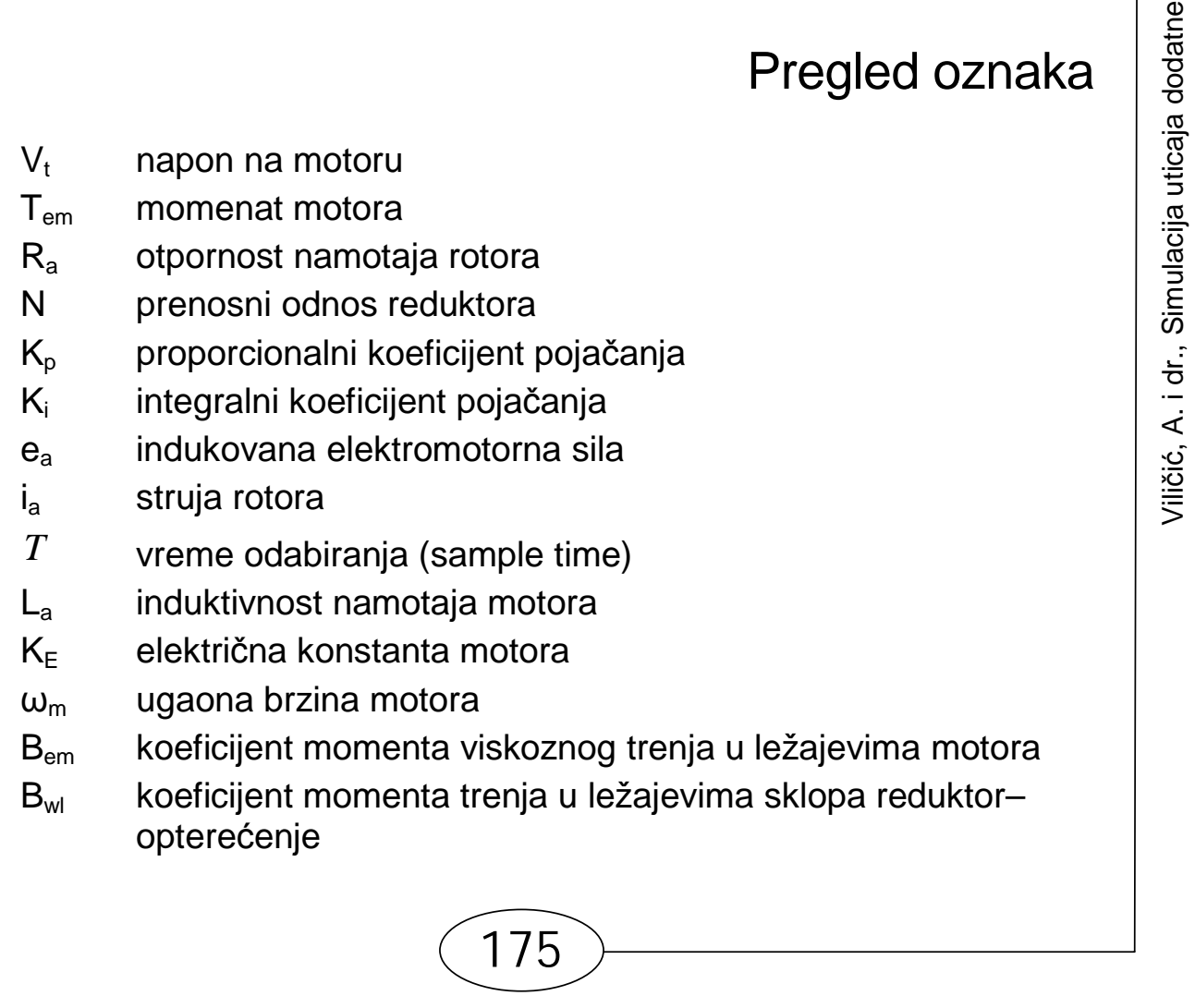


$\mathrm{J}_{\mathrm{em}} \quad$ momenat inercije rotora motora

$\mathrm{J} \quad$ ukupni momenat inercije sveden na rotor motora

B ukupni momenat viskoznog trenja sveden na rotor motora

$\mathrm{K}_{\mathrm{T}} \quad$ mehanička konstanta motora

$\tau_{m} \quad$ mehanička vremenska konstanta

$\tau_{m 1} \quad$ električna vremenska konstanta motora

s operator Laplasove transformacije

z operator z-transformacije

\section{Opis sistema}

Servosistem daljinski upravljane modularne borbene platforme koristi se za pokretanje borbenog i neborbenog dela po azimutu. Baziran je na elektromotornom pogonu sa regulatorom izvedenim na osnovu digitalnog upravljanja realizovanog mikrokontrolerski.

U ovom radu biće prezentovana simulacija pogona borbenog dela obrtne platforme po azimutu. Simulacija servositema i regulatora u svim režimima rada deo je procesa projektovanja i praktične realizacije servosistema. Zahvaljujući tome nije umanjen generalizovani pristup koji opisuje projektovanje i realizaciju stvarnih servosistema. Simulacija je samo jedan deo čitavog procesa od ideje do realizacije, koji služi za sagledavanje mogućnosti sistema i daje početne vrednosti (radne tačke) za podešavanje parametara sistema u praktičnoj realizaciji. Vrednosti parametara simulacije nisu i krajnje realizovane vrednosti parametara servosistema, jer se u simulaciji uvek radi sa linearizovanim modelom kojem su dodate neke nelinearnosti, a ne sa realnim sistemom.

Kao izvršni organ koristi se jednosmerni servomotor sa permanentnim magnetom u pobudnom kolu. Davač ugaone brzine je inkrementalni enkoder koji podatke daje u digitalnom obliku [1]. Davač ugaone pozicije je apsolutni enkoder. Vrednost struje rotora meri se analognim davačem.

Servosistem modularne obrtne platforme realizovan je kao digitalni servoregulator sa navedenim izvršnim organima i davačima. Upravljanje izvršnim organima realizovano je kroz povratne petlje po struji rotora, brzini rotora elektromotora i ugaonoj poziciji izlaznog vratila. Svaka unutrašnja petlja izvršava se najmanje deset puta brže od nadređene petlje. To znači da se radi o digitalnom sistemu upravljanja sa odabiračima različite brzine [2]. 


\section{Matematički model servosistema za pokretanje modularne obrtne platforme po azimutu}

Karakteristike ugrađenog pogonskog motora Maxon RE75 prikazane su u tabeli 1 [3].

Tabela 1

Karakteristike motore Maxon RE75

Table 1

Maxon RE75 motor characteristics

\begin{tabular}{|l|l|l|}
\hline Karakteristika & Oznaka & Vrednost \\
\hline Nominalni napon (Nominal voltage) & $\mathrm{V}_{\text {nom }}$ & $24[\mathrm{~V}]$ \\
\hline Nominalna brzina (Nominal speed) & $\omega_{\text {nom }}$ & $2510[\mathrm{o} / \mathrm{min}]$ \\
\hline Nominalni momenat (Nominal torque) & $\mathrm{T}_{\text {nom }}$ & $0,63[\mathrm{Nm}]$ \\
\hline Nominalna struja (Nominal current) & $\mathrm{I}_{\text {nom }}$ & $8,37[\mathrm{~A}]$ \\
\hline Otpornost namotaja (Terminal resistance) & $\mathrm{R}_{\mathrm{a}}$ & $0,181[\Omega]$ \\
\hline Induktivnost namotaja (Terminal inductance) & $\mathrm{L}_{\mathrm{a}}$ & $0,076[\mathrm{mH}]$ \\
\hline Konstanta momenta (Torque constant) & $\mathrm{K}_{\mathrm{T}}$ & $0,0799[\mathrm{Nm} / \mathrm{A}]$ \\
\hline Konstanta brzine (Speed constant) & $1 / \mathrm{K}_{\mathrm{E}}$ & $119[\mathrm{o} / \mathrm{min} / \mathrm{V}]$ \\
\hline $\begin{array}{l}\text { Mehanička vremenska konstanta } \\
\text { (Mechanical time constant) }\end{array}$ & $I_{\mathrm{mot}}$ & $4,25[\mathrm{~ms}]$ \\
\hline Momenat inercije rotora (Rotor inertia) & & $0,00015\left[\mathrm{kgm}{ }^{2}\right]$ \\
\hline Struja starta rotora (Starting current) & $\mathrm{J}_{\mathrm{m}}$ & $0,518[\mathrm{~A}]$ \\
\hline
\end{tabular}

DC motor sa permanentnim magnetom upravljan strujom rotora može se predstaviti jednačinama [1]:

$$
\begin{aligned}
& V_{t}(t)=e_{a}(t)+R_{a} i_{a}(t)+\frac{L d i_{a}(t)}{d t} \\
& e_{a}(t)=K_{E} \omega_{m}(t) \\
& T_{e m}(t)=\left(B_{e m}+B_{W L}\right) \omega_{m}(t)+\left(J_{e m}+J_{W L}\right) \frac{d \omega_{m}(t)}{d t}=B \omega_{m}(t)+J \frac{d \omega_{m}(t)}{d t} \\
& T_{e m}(t)=K_{T} i_{a}(t)
\end{aligned}
$$

Koristeći Laplasovu transformaciju, sa pretpostavkom da je električna vremenska konstanta znatno manja od mehaničke vremenske konstante (bar 10 puta), prenosne funkcije DC motora se mogu izraziti u sledećem obliku:

$$
\begin{aligned}
& \omega_{m}(s)=\frac{K_{T}}{B} \frac{1}{1+\tau_{m} s} I_{a}(s), \\
& I_{a}(s)=K_{2} \frac{1+\tau_{m} s}{1+\tau_{m 1} s} V_{t}(s)
\end{aligned}
$$


Pri čemu je:

$$
\begin{aligned}
& K_{2}=\frac{B}{K_{E} K_{T}+R_{a} B}, \\
& \tau_{m}=\frac{J}{B} \\
& \tau_{m 1}=\frac{R_{a} B}{K_{E} K_{T}+R_{a} B} \tau_{m}
\end{aligned}
$$

Linearizovane prenosne funkcije objekta upravljanja korišćene pri simulaciji imaju oblik:

$$
\begin{aligned}
& \frac{I_{m}}{V_{t}(s)}=\frac{K_{2}\left(1+\tau_{m} s\right)}{\left(1+\tau_{m 1} s\right)}=G_{1}(s) \quad i \\
& \frac{\omega_{m}(s)}{I_{m}(s)}=\frac{K}{\left(1+\tau_{m} s\right)}=G_{2}(s)
\end{aligned}
$$

gde je $\mathrm{K}=\mathrm{K}_{\mathrm{T}} / \mathrm{B}$.

Motor pokreće obrtnu platformu koja ima momenat inercije $\mathrm{J}_{\mathrm{WI}}=40\left[\mathrm{kgm}^{2}\right]$. Ugrađen je reduktor redukcionog odnosa $\mathrm{N}=163$. Izmereni startni momenat sa ugrađenim motorom za pokretanje platforme je $M_{\mathrm{tr}}=50[\mathrm{Nm}]$. Kada se platforma kreće (sa ugrađenim motorom) konstantnom brzinom od $15[0 / s]$ izmeren je momenat $20[\mathrm{Nm}]$. S obzirom na to da se platforma kreće konstantnom brzinom član uz izvod brzine u (3) je 0, pa je izmereni momenat posledica ukupnog trenja na strani platforme.

Koristeći podatke iz tabele 1 i podatke o opterećenju i reduktoru moguće je naći parametre koji daju egzaktnu prenosnu funkciju za objekat upravljanja (motor sa opterećenjem).

Iz (1) i (2) za nominalne vrednosti struje i napona kada je izvod struje 0 (struja konstantna) nalazimo

$$
K_{E}=\frac{e_{\text {nom }}}{\omega_{\text {nom }}}=\frac{24-R I_{\text {nom }}}{262,84}=\frac{24-1,515}{262,84}=85,5 \cdot 10^{-3}[\mathrm{Vs}]
$$

Iz (4) za nominalne vrednosti nalazimo

$$
K_{T}=\frac{T_{\text {nom }}}{I_{\text {nom }}}=\frac{630 \cdot 10^{-3}}{8,37}=75,26 \cdot 10^{-3}[\mathrm{Nm} / \mathrm{A}] .
$$


Koeficijent trenja motora nalazimo iz

$$
B_{m}=\frac{J_{m}}{\tau_{m o t}}=\frac{0,15 \cdot 10^{-3}}{4,25}=35,3 \cdot 10^{-3}[\mathrm{Nms}] .
$$

Izmereni momenat trenja platforme pri kretanju konstantnom brzinom je ukupni momenat platforme i motora, pa odatle dobijamo koeficijent trenja na strani osovine rotora

$$
B=B_{m}+B_{w L}=\frac{M_{t r}}{\omega} \frac{1}{N}=\frac{15}{0,35} \frac{1}{163}=263 \cdot 10^{-3}[\mathrm{Nms}] .
$$

Momenat inercije sveden na osovinu rotora motora je [4]

$$
J=J_{m}+\frac{J_{w l}}{N^{2}}=0,15 \cdot 10^{-3}+\frac{40}{163^{2}}=1,65 \cdot 10^{-3}\left[\mathrm{kgm}^{2}\right] .
$$

Sada nalazimo mehaničku vremensku konstantu

$$
\tau_{m}=\frac{J}{B}=\frac{1,65 \cdot 10^{-3}}{263 \cdot 10^{-3}}=6,3 \cdot 10^{-3}[\mathrm{~s}]
$$

\section{Prenosna funkcija bez dodate iduktivnosti}

Električna vremenska konstanta motora je

$$
\tau_{\text {em }}=\frac{L}{R}=\frac{76 \cdot 10^{-6}}{181 \cdot 10^{-3}}=0,42 \cdot 10^{-3}[\mathrm{~s}]
$$

što zadovoljava uslov da je bar 10 puta manja od mehaničke vremenske konstante.

Smenom ovako dobijenih vrednosti u (7) i (9) dobijamo

$$
\tau_{m 1}=5,55 \cdot 10^{-3}[\mathrm{~s}] \text { i K } 2=4,86[1 / \Omega] \text {. }
$$

Smenom dobijenih vrednosti koeficijenata u (10) i (11) dobijamo prenosne funkcije motora

$$
\begin{aligned}
& \frac{I_{m}(s)}{V_{m}(s)}=\frac{5,52 \cdot(158,7+s)}{180+s} i \\
& \frac{\omega_{m}(s)}{I_{m}(s)}=\frac{45,4}{158,7+s}
\end{aligned}
$$

Za slučaj da se ne zanemaruje električna vremenska konstanta u odnosu na mehaničku vremensku konstantu iz (1) do (4) dobijamo prenosnu funkciju: 


$$
\begin{aligned}
& \frac{I_{m}[s]}{V_{m}[s]}=\frac{(B / J+s) / L}{\frac{K_{e} K_{t}+B R}{J L}+\frac{J R+L B}{J L} s+s^{2}}=\frac{(158,7+s) \cdot 13158}{827537+2543 s+s^{2}}= \\
& =\frac{(158,7+s) \cdot 13158}{(s+383)(s+2159)}
\end{aligned}
$$

$\mathrm{Na}$ ovaj način dobijena je prenosna funkcija sa dva realna pola čija je udaljenost manja od 6 puta, pa se po pravilu veći pol ne bi trebao zanemarivati u analizi sistema i sintezi regulatora.

\section{Prenosna funkcija sa dodatom induktivnošću $150 \mu \mathrm{H}$}

$\mathrm{Na}$ red sa rotorskim namotajem povezana je dodatna induktivnost od $150 \mu \mathrm{H}$, unutrašnje otpornosti namotaja $60 \mathrm{~m} \Omega$, tako da je nova električna vremenska konstanta: $\tau_{\text {em }}=\frac{L}{R}=\frac{225 \cdot 10^{-6}}{240 \cdot 10^{-3}}=0,937 \cdot 10^{-3}[\mathrm{~s}]$

Smenom ovako dobijenih vrednosti u (7) i (9) dobijamo:

$$
\tau_{m 1}=5.67 \cdot 10^{-3}[\mathrm{~s}] \text { i K }{ }_{2}=3.78[1 / \Omega] \text {. }
$$

Smenom dobijenih vrednosti koeficijenata u (10) i (11) dobijamo prenosne funkcije motora:

$$
\begin{aligned}
& \frac{I_{m}(s)}{V_{m}(s)}=\frac{4,2 \cdot(158,7+s)}{176,3+s} \mathrm{i} \\
& \frac{\omega_{m}(s)}{I_{m}(s)}=\frac{45,4}{158,7+s}
\end{aligned}
$$

S obzirom na to da se dodavanjem redne induktivnosti menja električna vremenska konstanta i postaje bliža mehaničkoj (nije bar 10 puta manja), potrebno je analizirati ovaj uticaj i opravdanost zanemarivanja u (10). U slučaju da se ne zanemaruje električna vremenska konstanta u odnosu na mehaničku vremensku konstantu iz (1) do (4) dobijamo prenosnu funkciju:

$$
\begin{aligned}
& \frac{I_{m}[s]}{V_{m}[s]}=\frac{(B / J+s) / L}{\frac{K_{e} K_{t}+B R}{J L}+\frac{J R+L B}{J L} s+s^{2}}=\frac{(158,7+s) \cdot 4444}{187353+1226 s+s^{2}}= \\
& =\frac{(s+158,7) \cdot 4444}{(s+179)(s+1047)}
\end{aligned}
$$

sa dva realna pola čija je udaljenost manja od 6 puta, pa se, po pravilu, veći pol ne bi trebao zanemarivati u analizi sistema i sintezi regulatora. 


\section{Prenosna funkcija sa dodatom induktivnošću $500 \mu \mathrm{H}$}

$\mathrm{Na}$ red sa rotorskim namotajem povezana je dodatna induktivnost od $500[\mu \mathrm{H}]$, unutrašnje otpornosti namotaja $80[\mathrm{~m} \Omega]$, tako da je nova električna vremenska konstanta: $\tau_{\text {em }}=\frac{L}{R}=\frac{576 \cdot 10^{-6}}{260 \cdot 10^{-3}}=2,21 \cdot 10^{-3}[\mathrm{~s}]$

Smenom ovako dobijenih vrednosti u (7) i (9) dobijamo:

$$
\tau_{m 1}=5,75 \cdot 10^{-3}[\mathrm{~s}] \text { i K } 2=3,5[1 / \Omega] .
$$

Smenom dobijenih vrednosti koeficijenata u (10) i (11) dobijamo prenosne funkcije motora:

$$
\begin{aligned}
& \frac{I_{m}(s)}{V_{m}(s)}=\frac{3,83 \cdot(158,7+s)}{173,6+s} \mathrm{i} \\
& \frac{\omega_{m}(s)}{I_{m}(s)}=\frac{45,4}{158,7+s}
\end{aligned}
$$

S obzirom na to da se dodavanjem redne induktivnosti menja električna vremenska konstanta i postaje bliža mehaničkoj (nije bar 10 puta manja) potrebno je analizirati ovaj uticaj i opravdanost zanemarivanja u (10). U slučaju da se ne zanemaruje električna vremenska konstanta u odnosu na mehaničku vremensku konstantu iz (1) do (4) dobijamo prenosnu funkciju:

$$
\begin{aligned}
& \frac{I_{m}[s]}{V_{m}[s]}=\frac{(B / J+s) / L}{\frac{K_{e} K_{t}+B R}{J L}+\frac{J R+L B}{J L} s+s^{2}}=\frac{(158,7+s) \cdot 1736}{78855+611,5 s+s^{2}}= \\
& =\frac{(s+158,7) \cdot 1736}{(s+184,7)(s+426,7)}
\end{aligned}
$$

U ovom slučaju prenosna funkcija ima par realnih korena koji su udaljeni samo 2,5 puta, pa se nijedan ne bi smeo zanemariti pri analizi sistema i sintezi regulatora [1]. 


\section{Parametri simuliranog modela servosistema i strukturni blok-dijagrami}

Struja je elektronski ograničena na 20[A]. Kao davač vrednosti struje koristi se strujni transformator LEM odnosa transformacije 1:1000 i otpornik otpornosti $220[\Omega]$. Pad napona na ovom otporniku vodi se na 10 -bitni $A D$ konvertor koji meri do 3,3[V]. Prenosna funkcija ovog davača je $V_{\text {mer }} / I_{r}=220 / 1000=0,22[\mathrm{~V} / \mathrm{A}]$, a rezolucija je 3,3[V]/1024=3,22[mV] po bitu, što je 3,22/220=14,6[mA/bit].

Davač brzine okretanja vratila motora je inkrementalni enkoder HEDS sa 2000 impulsa po krugu. To znači da je rezolucija merenja ugaone brzine vratila motora $(2 \pi / 2000) / 0,002=\pi / 2[\mathrm{rad} / \mathrm{s}]$. Ona je nedovoljna, ali se softverskim metodama, kao i merenjem trenutka poslednjeg impulsa, rezolucija može poboljšati do 5 puta. Zato je u simulaciji primenjen model inkrementalnog enkodera rezolucije $\pi / 6[\mathrm{rad} / \mathrm{s}]$.

$\mathrm{U}$ simulacioni model servosistema uneti su parametri modela (16) $\mathrm{i}$ skraćenog modela (10). Takođe, simulirane su i nelinearnosti tipa zona neosetljivosti, elektronskog ograničenja struje na 20[A] i mrtvog hoda zupčanika (backslash).

Simulacija je realizovana iz dva dela: strujne petlje i brzinske petlje. Prvo se vrši simulacija i podešavanje strujne petlje, a zatim simulacija i podešavanje brzinske petlje. Primenjeni redosled i postupak simulacije identičan je postupku koji se primenjuje pri podešavanju realnog servosistema [5]. Na slici 1 data je strukturna blok-šema električnog servosistema sa digitalnim regulatorom za brzinsko upravljanje modularnom obrtnom platformom, dok je na slici 2 prikazana strukturna blok- šema električnog servosistema sa digitalnim regulatorom sa izmeštenim proporcionalnim dejstvom za brzinsko upravljanje obrtnom platformom.

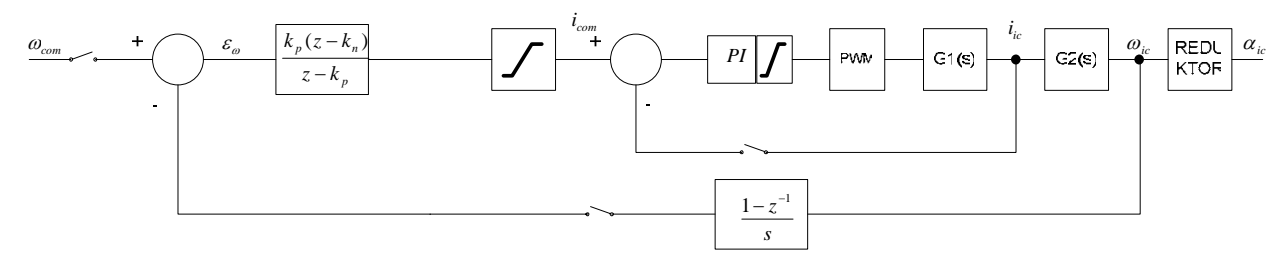

Slika 1 - Strukturna blok-šema električnog servosistema sa digitalnim regulatorom za brzinsko upravljanje modularnom obrtnom platformom

Figure 1 - Block schematics of the electrical servo drive with digital speed regulation for modular turret drive 


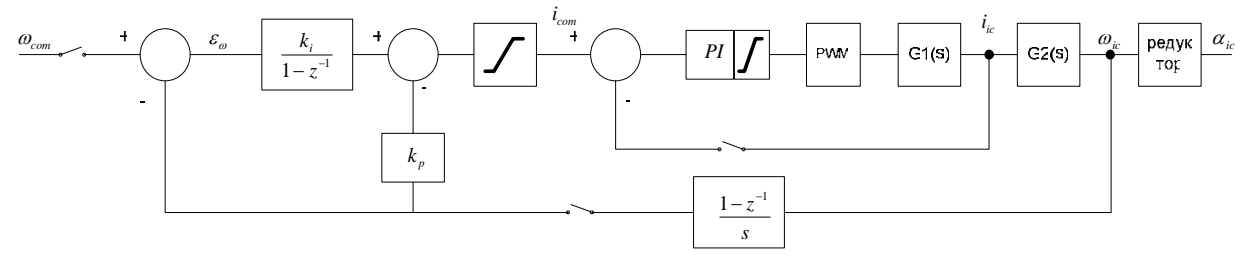

Slika 2 - Strukturna blok-šema električnog servosistema sa digitalnim regulatorom sa izmeštenim proporcionalnim dejstvom za brzinsko upravljanje modularnom turelom

Figure 2 - Block schematics of the digital speed regulation electrical servo drive with displaced proportional coefficient for modular turret drive

Blok-dijagrami digitalnog servosistema za pokretanje modularne daljinski upravljane turele uneti su u simulacioni alat (toolkit) programskog paketa LabView. $U$ ovako oformljeni simulacioni paket uneti su parametri simuliranog servosistema.

\section{Rezultati simulacije}

Simulirano je podešavanje parametara strujne petlje, a zatim brzinske petlje sa dve vrste regulatora. Sve simulacije su urađene za prenosne funkcije (10) i (16). Svaka simulacija i podešavanje parametara izvršeno je za sva tri slučaja induktivnosti (bez, $150[\mu \mathrm{H}]$ i $500[\mu \mathrm{H}])$.

Podešavanje parametara regulatora strujne petlje obavljeno je na način da se zadovolje sledeći zahtevi:

- odziv strujne petlje treba da ima aperiodičan oblik ili preskok do 10\%,

- u najviše 10 perioda odabiranja odziv strujne petlje treba da dostigne stacionarno stanje ili da greška padne na $10 \%$,

- greška stacionarnog stanja strujne petlje treba da bude manja od 10\%.

Referentne vrednosti (setpoint) za brzinsku petlju, kao i odzivi, dati su na izlaznom vratilu (izlaz reduktora).

$U$ zavisnosti od zahtevanog režima rada servosistema mogu se definisati i drugi zahtevi za odziv brzinske petlje. Tako je nekada potrebno da odziv bude što je moguće brži, pa i po cenu da preskok bude i $20 \%$. U nekim slučajevima je potrebno da odziv bude aperiodičan sa malom greškom (manjom od 1\%) stacionarnog stanja.

\section{Simulacija sistema bez dodate iduktivnosti}

Simulacijom je izvršeno podešavanje parametara strujnog regulatora $H(z)=\frac{0,04(z+0,05)}{z-0,97}$ pri periodu odabiranja 0,0002 [s]. Ovako podešen regulator upotrebljen je za snimanje odziva strujne petlje na pobudu tipa od- 
skočna pobuda, respektivno za model iz (16) i skraćeni model iz (10). Karakteristike pobuda su: amplituda 4[A], učestanost 20[Hz] i fazni pomeraj $0\left[{ }^{0}\right]$.

Na graficima (slika 3 i 4, kao i 8, 9, 13 i 14) prikazan je odziv strujne petlje. Crnim grafikom prikazana je vrednost reference (setpointa) struje (oznaka 1), zelenim - strujna greška (oznaka 2), a plavim - odziv (oznaka 3), odnosno vrednost struje.

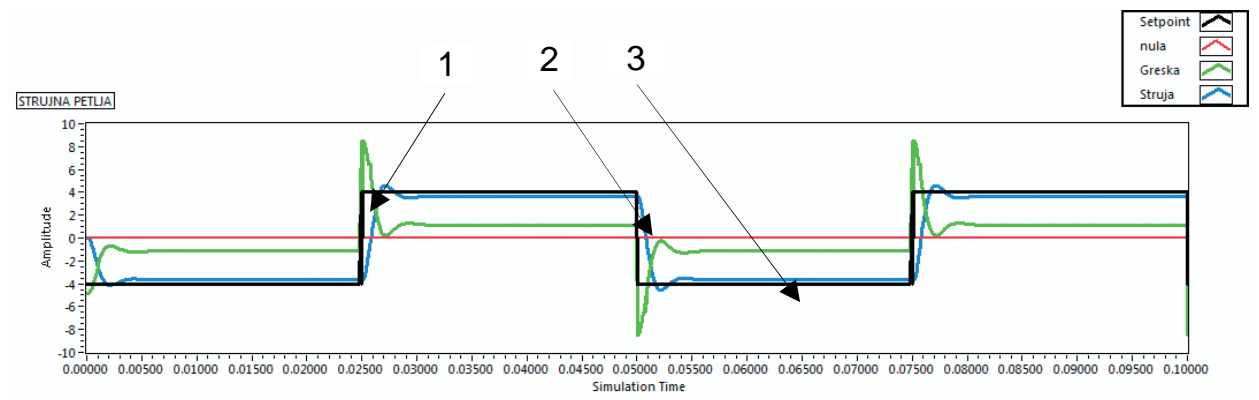

Slika 3 - Odziv modela (16) na odskočnu pobudu Figure 3 - Model (16) Step response

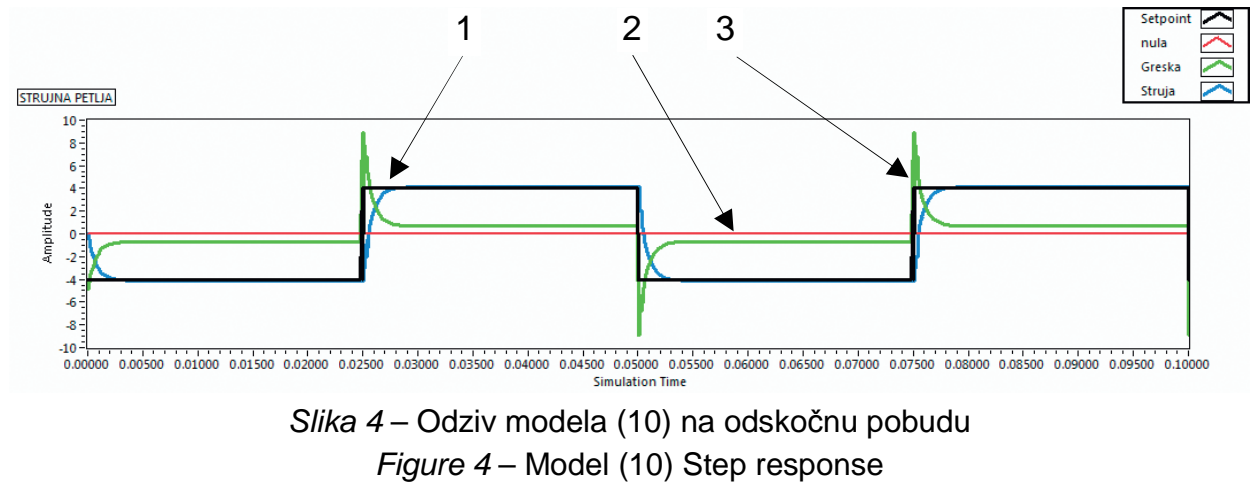

Simulacijom je izvršeno podešavanje parametara brzinskog regulatora, strukture kao na slici $1, H_{\omega}(z)=\frac{6(z-0,3)}{z-0,95}$ pri periodu odabiranja brzinske petlje $0,002[s]$. Ovako podešen regulator upotrebljen je za snimanje odziva brzinske petlje na pobudu tipa odskočna pobuda, respektivno za model iz (16) i skraćeni model iz (10). Karakteristike pobuda su: amplituda 0,5[rad], učestanost $5[\mathrm{~Hz}]$ i fazni pomeraj $162\left[^{0}\right]$.

Na graficima (slike 5, 6 i 7,kao i 10, 11 i 12, odnosno 15, 16, 17, 18,19 i 20) prikazan je odziv brzinske petlje. Crnim grafikom prikazana je vrednost reference (setpointa) struje (oznaka 1), crvenim - vrednost brzine (oznaka 2) koju čita digitalni regulator, žutim - greška brzine u digital- 
nom regulatoru (oznaka 3), a plavim - odziv, odnosno vrednost ugaone brzine platforme (oznaka 4).

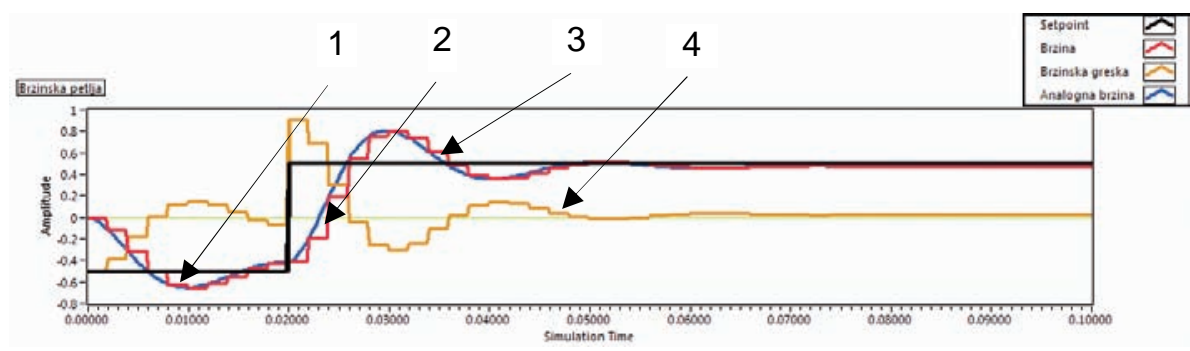

Slika 5 - Odziv brzinske petlje modela (16) i brzinskog regulatora sa slike 1 na odskočnu pobudu Figure 5 - Model (16) speed loop step response with equalizer as in Figure 1

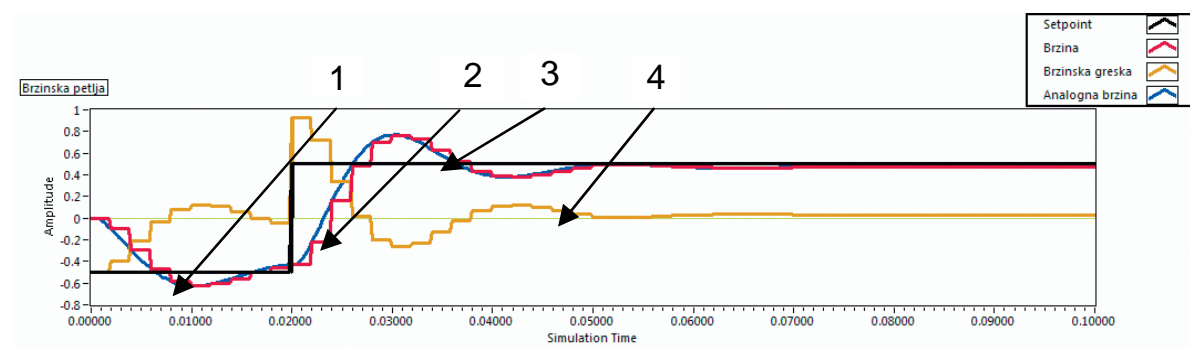

Slika 6 - Odziv brzinske petlje modela (10) i brzinskog regulatora sa slike 1 na odskočnu pobudu Figure 6 - Model (10) speed loop step response with equalizer as in Figure 1

Sa slika 5 i 6 vidi se da nema razlike u obliku odziva petlje po ugaonoj brzini bez obzira na primenjeni model u simulaciji.

Simulacijom je izvršeno podešavanje parametara brzinskog regulatora, strukture kao na slici 2 , sa parametrima $\mathrm{K}_{\mathrm{i}}=2,5 \mathrm{i} \mathrm{K}_{\mathrm{p}}=6$ pri periodu odabiranja brzinske petlje 0,002[s]. Ovako podešen regulator upotrebljen je za snimanje odziva brzinske petlje na pobudu tipa odskočna pobuda (slika 7), respektivno za model iz (16) i skraćeni model iz (10). Karakteristike pobuda su: amplituda 0,5[rad], učestanost 5[Hz] i fazni pomeraj $162\left[^{0}\right]$.

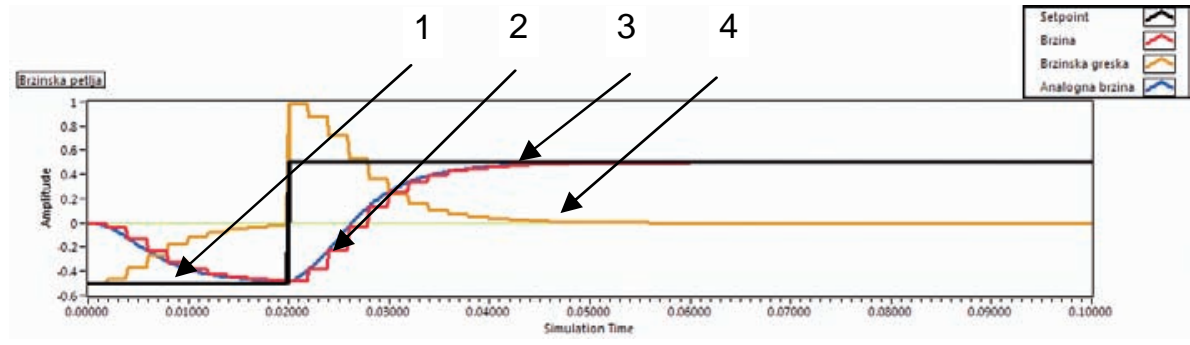

Slika 7 - Odziv brzinske petlje modela (16) i brzinskog regulatora sa slike 2 na odskočnu pobudu Figure 7 - Model (16) speed loop step response with equalizer as in Figure 2 


\section{Simulacija sistema sa dodatnom rednom iduktivnosti od $150 \mu \mathrm{H}$}

Simulaciom je izvršeno podešavanje parametara strujnog regulatora $H(z)=\frac{0,04(z+0,05)}{z-0,97}$ pri periodu odabiranja 0,0002[s]. Ovako podešen regulator upotrebljen je za snimanje odziva strujne petlje na pobudu tipa odskočna pobuda (slike 8 i 9), respektivno za model iz (16) i skraćeni model iz (10). Karakteristike pobuda su: amplituda 4[A], učestanost $20[\mathrm{~Hz}]$ i fazni pomeraj $\left.0{ }^{0}\right]$.

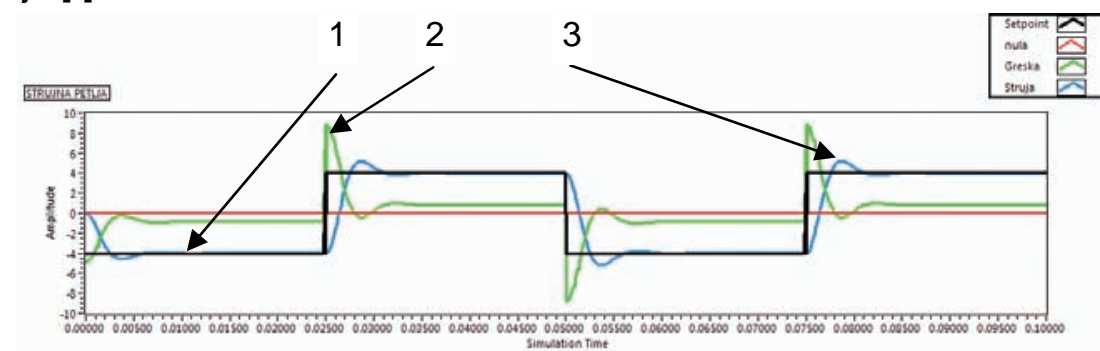

Slika 8 - Odziv modela (16) na odskočnu pobudu (dodatna induktivnost $150 \mu \mathrm{H}$ ) Figure 8 - Model (16) step response (added inductance $150 \mu \mathrm{H}$ )

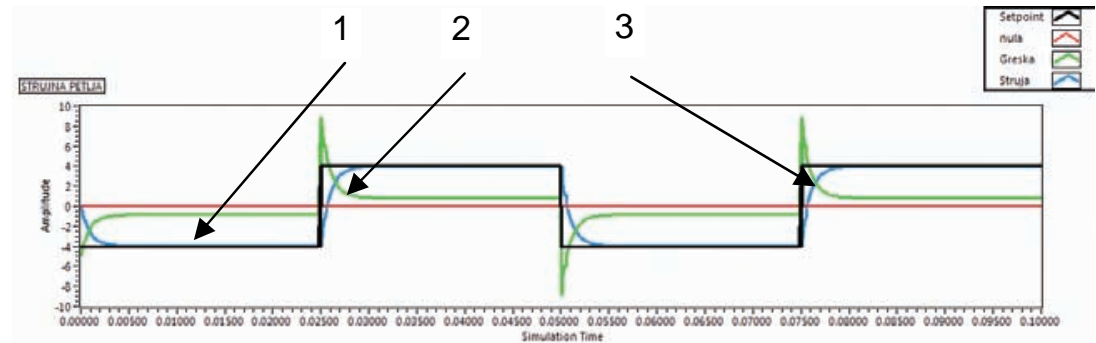

Slika 9 - Odziv modela (10) na odskočnu pobudu (dodatna induktivnost $150 \mu \mathrm{H}$ ) Figure 9 - Model (10) step response (added inductance 150 $\mu \mathrm{H}$ )

Ovako podešena strujna petlja uneta je u model brzinske petlje regulatora oblika kao na slici 1.

Simulacijom je izvršeno podešavanje parametara brzinskog regulatora, strukture kao na slici $1, H_{\omega}(z)=\frac{6(z-0,3)}{z-0,95}$ pri periodu odabiranja brzinske petlje $0,002[s]$. Ovako podešen regulator je upotrebljen za snimanje odziva brzinske petlje na pobudu tipa odskočna pobuda (slika 10 i 11), respektivno za model iz (16) i skraćeni model iz (10). Karakteristike pobuda su: amplituda $0,5[\mathrm{red}]$, učestanost $5[\mathrm{~Hz}]$ i fazni pomeraj $162\left[^{0}\right]$. 


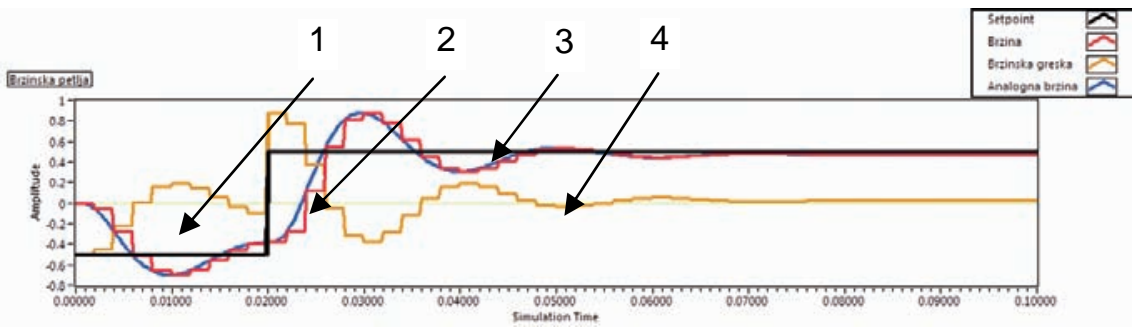

Slika 10 - Odziv brzinske petlje modela (16) i brzinskog regulatora sa slike 1 na odskočnu pobudu (dodatna induktivnost $150 \mu \mathrm{H}$ )

Figure 10 - Model (16) speed loop step response with equalizer as in Figure 1 (added inductance $150 \mu \mathrm{H}$ )

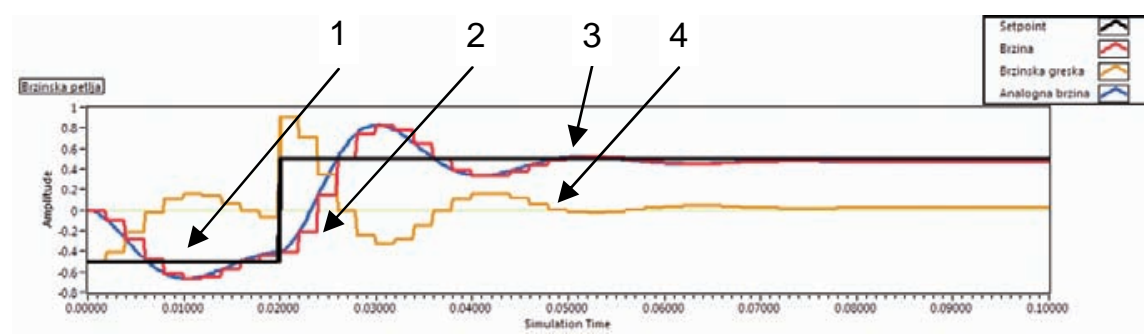

Slika 11 - Odziv brzinske petlje modela (10) i brzinskog regulatora sa slike 1 na odskočnu pobudu (dodatna induktivnost $150 \mu \mathrm{H}$ )

Figure 11 - Model (10) speed loop step response with equalizer as in Figure 1 (added inductance $150 \mu \mathrm{H}$ )

Sa slika 10 i 11 vidi se da nema razlike u obliku odziva petlje po ugaonoj brzini, bez obzira na primenjeni model u simulaciji.

Simulacijom je izvršeno podešavanje parametara brzinskog regulatora, strukture kao na slici 2 , sa parametrima $\mathrm{K}_{\mathrm{i}}=2,5$ i $\mathrm{K}_{\mathrm{p}}=6$ pri periodu odabiranja brzinske petlje 0,002 [s]. Ovako podešen regulator upotrebljen je za snimanje odziva brzinske petlje na pobudu tipa odskočna pobuda (slika 12), respektivno za model iz (16) i skraćeni model iz (10). Karakteristike pobuda su: amplituda 0,5 [rad], učestanost 5[Hz] i fazni pomeraj 162 [0].

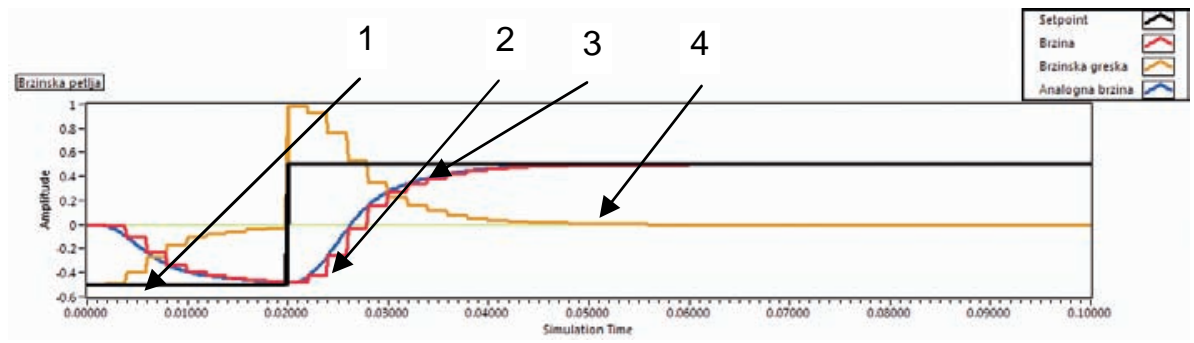

Slika 12 - Odziv brzinske petlje modela (16) i brzinskog regulatora sa slike 2 na odskočnu pobudu (dodatna induktivnost $150 \mu \mathrm{H}$ )

Figure 12 - Model (16) speed loop step response with equalizer as in Figure 2 (added inductance 150 $\mu \mathrm{H}$ ) 


\section{Simulacija sistema sa dodatnom rednom iduktivnosti od $500 \mu \mathrm{H}$}

Simulacijom je izvršeno podešavanje parametara strujnog regulatora $H(z)=\frac{0,05(z+0,15)}{z-0,95}$ pri periodu odabiranja 0,0002[s]. Ovako podešen regulator upotrebljen je za snimanje odziva strujne petlje na pobudu tipa odskočna pobuda (slike 13 i 14), respektivno za model iz (16) i skraćeni model iz (10). Karakteristike pobuda su: amplituda 4[A], učestanost $20[\mathrm{~Hz}]$ i fazni pomeraj $0\left[^{0}\right]$.

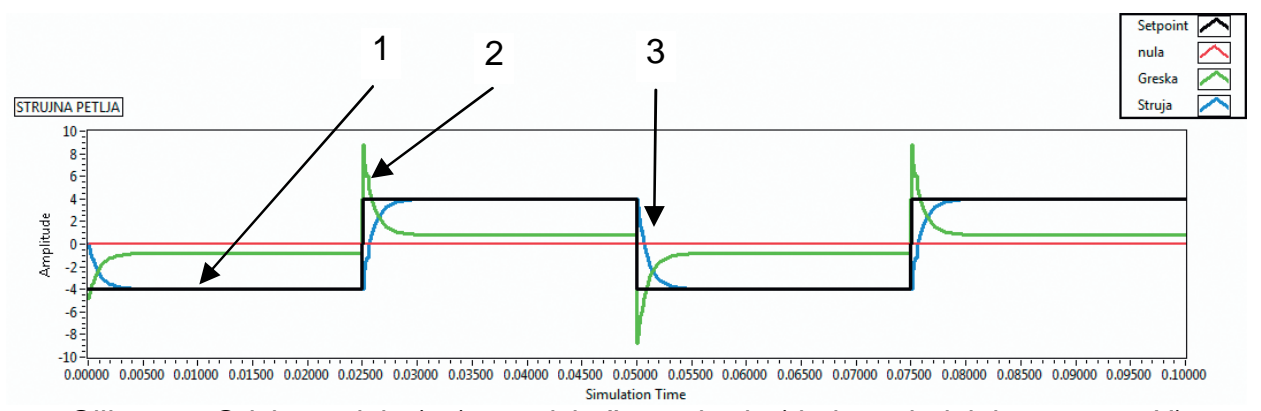

Slika 13 - Odziv modela (10) na odskočnu pobudu (dodatna induktivnost $500 \mu \mathrm{H}$ )

Figure 13 - Model (10) step response (added inductance $500 \mu \mathrm{H}$ )

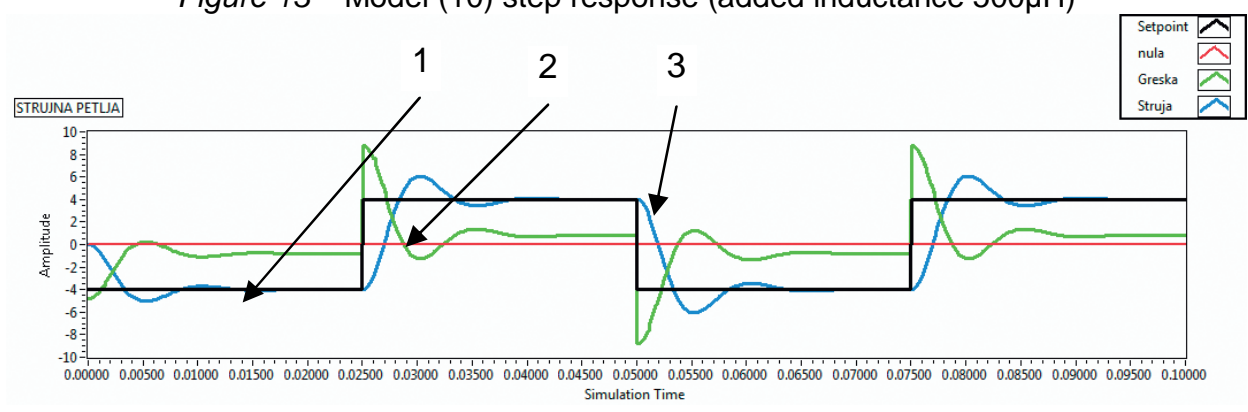

Slika 14 - Odziv modela (16) na odskočnu pobudu (dodatna induktivnost $500 \mu \mathrm{H}$ ) Figure 14 - Model (16) step response (added inductance $500 \mu \mathrm{H}$ )

Ovako podešena strujna petlja uneta je $u$ model brzinske petlje regulatora oblika kao na slici 1.

Simulacijom je izvršeno podešavanje parametara brzinskog regulatora (slike 15 i 16), strukture kao na slici $1, H_{\omega}(z)=\frac{6(z-0,3)}{z-0,95}$ pri periodu odabiranja brzinske petlje $0,002[s]$. Ovako podešen regulator upotrebljen 
je za snimanje odziva brzinske petlje na pobudu tipa odskočna pobuda, respektivno za model iz (16) i skraćeni model iz (10). Karakteristike pobuda su: amplituda 0,5[rad], učestanost 5[Hz] i fazni pomeraj $162\left[{ }^{0}\right]$.

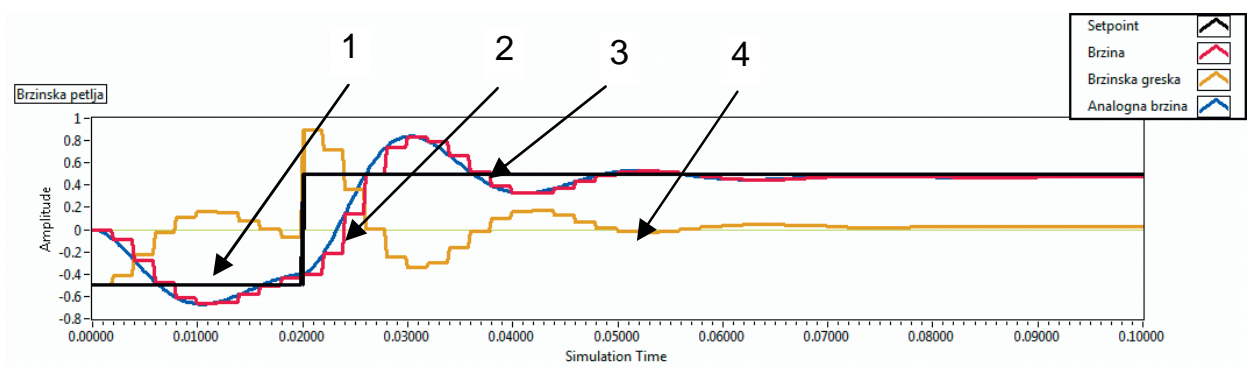

Slika 15 - Odziv brzinske petlje modela (10) i brzinskog regulatora sa slike 1 na odskočnu pobudu (dodatna induktivnost $500 \mu \mathrm{H}$ )

Figure Figure 15 - Model (10) speed loop step response with equalizer as in Figure 1 (added inductance $500 \mu \mathrm{H}$ )

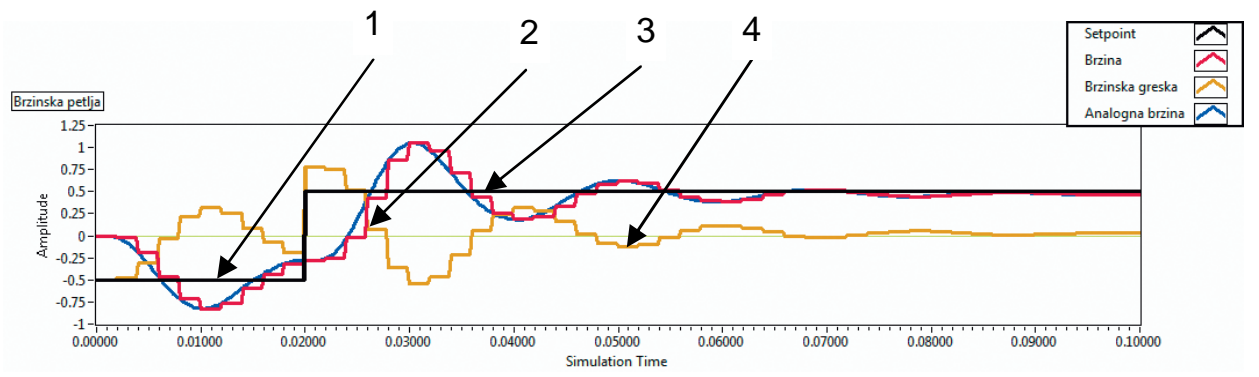

Slika 16 - Odziv brzinske petlje modela (16) i brzinskog regulatora sa slike 1 na odskočnu pobudu (dodatna induktivnost $500 \mu \mathrm{H}$ )

Figure 16 - Model (16) speed loop step response with equalizer as in Figure 1 (added inductance $500 \mu \mathrm{H}$ )

Na slikama 15 i 16 vidi se da postoji razlika u obliku odziva u zavisnosti od simulacionog modela. To govori da se ne sme zanemariti uticaj električne vremenske konstante pri simulaciji ili projektovanju.

Sa izmenjenim parametrima regulatora $H_{\omega}(z)=\frac{1,8(z-0,4)}{z-0,97}$ dobijaju se odzivi kao na slikama 17 i 18. 


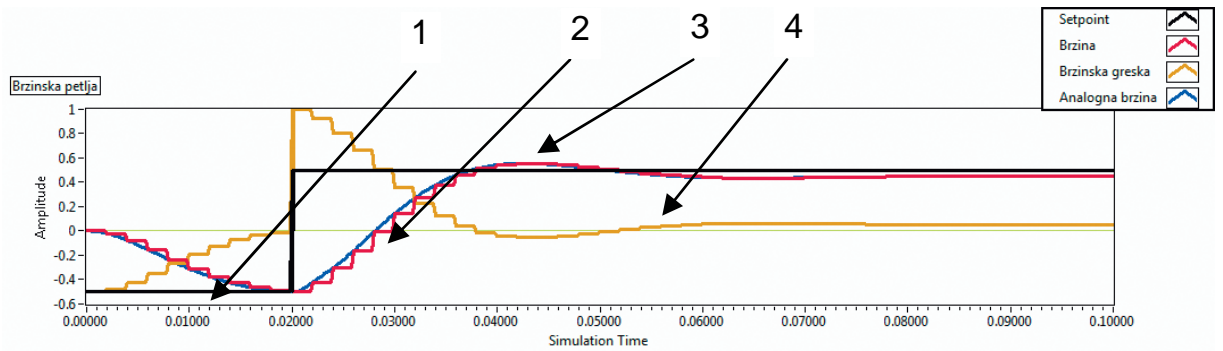

Slika 17 - Odziv brzinske petlje modela (10) i brzinskog regulatora sa slike 1 na odskočnu pobudu (dodatna induktivnost $500 \mu \mathrm{H}$ )

Figure 17 - Model (10) speed loop step response with equalizer as in Figure 1 (added inductance $500 \mu \mathrm{H}$ )

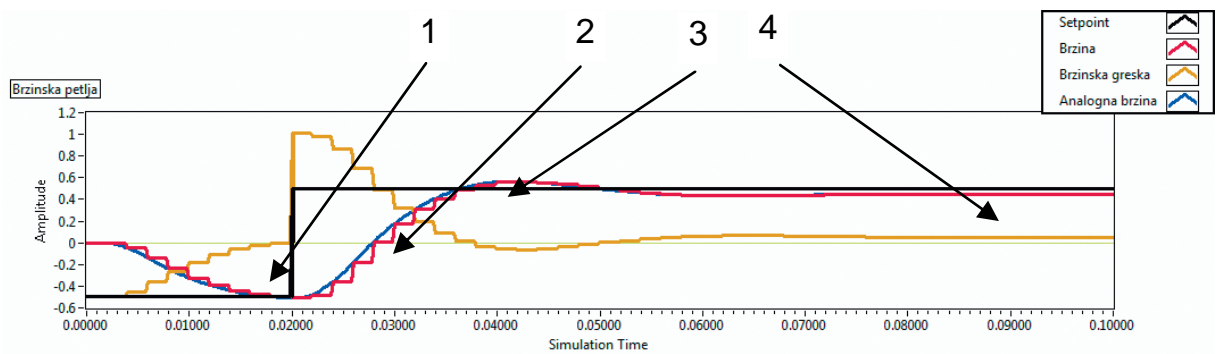

Slika 18 - Odziv brzinske petlje modela (10) i brzinskog regulatora sa slike 1 na odskočnu pobudu (dodatna induktivnost $500 \mu \mathrm{H}$ )

Figure 18 - Model (10) speed loop step response with equalizer as in Figure 1 (added inductance $500 \mu \mathrm{H}$ )

Simulacijom je izvršeno podešavanje parametara brzinskog regulatora, strukture kao na slici 2, sa parametrima $\mathrm{K}_{\mathrm{i}}=3$ i $\mathrm{K}_{\mathrm{p}}=5$ pri periodu odabiranja brzinske petlje 0,002[s]. Ovako podešen regulator upotrebljen je za snimanje odziva brzinske petlje na pobudu tipa odskočna pobuda (slike $19 \mathrm{i}$ 20), respektivno za model iz (16) i skraćeni model iz (10). Karakteristike pobuda su: amplituda 0,5[rad], učestanost $5[\mathrm{~Hz}]$ i fazni pomeraj $162\left[^{0}\right]$.

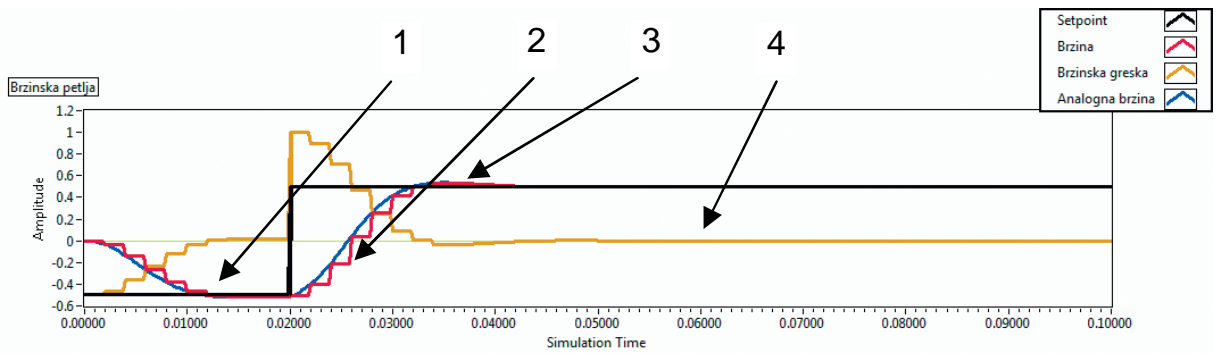

Slika 19 - Odziv brzinske petlje modela (16) i brzinskog regulatora sa slike 2 na odskočnu pobudu (dodatna induktivnost $500 \mu \mathrm{H}$ )

Figure 19 - Model (16) speed loop step response with equalizer as in Figure 2 (added inductance $500 \mu \mathrm{H}$ ) 


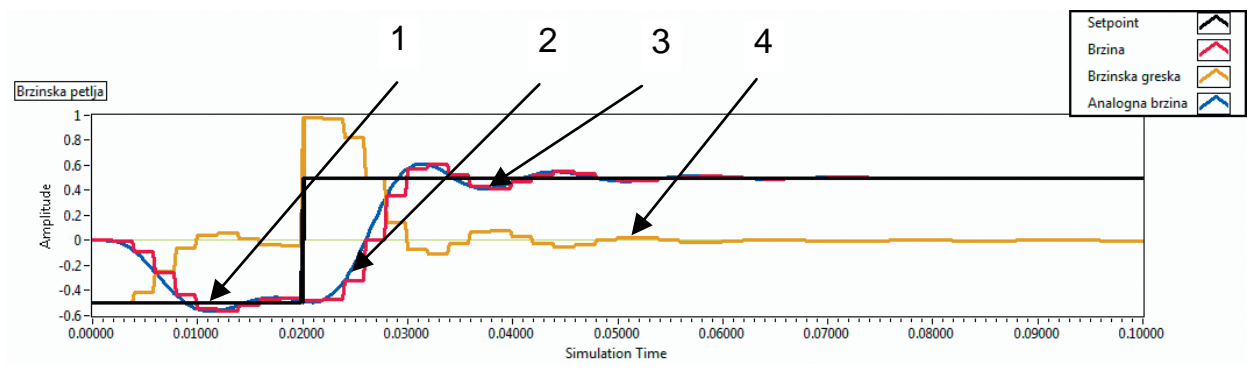

Slika 20 - Odziv brzinske petlje modela (16) i brzinskog regulatora sa slike 1 na odskočnu pobudu (dodatna induktivnost $500 \mu \mathrm{H}$ )

Figure 20 - Model (16) speed loop step response with equalizer as in Figure 1 (added inductance $500 \mu \mathrm{H}$ )

I u ovom slučaju vidimo da se ne može zanemariti električna vremenska konstanta, jer utiče na oblik odziva simuliranog modela.

Zaključak

U radu je prikazana simulacija realnog električnog servopogona sa digitalnim regulatorom koji je primenjen za pokretanje borbenog modula modularne obrtne platforme DALOS. Sistem je simuliran u alatu za simulaciju programskog paketa LabView. Simulirane su identifikovane prenosne funkcije realnog sistema (prenosne funkcija motora, davača struje i ugaone brzine), kao i nelinearnosti motora i reduktora. U radu su korišćene klasične metode matematičkog modeliranja servosistema, primenjena je metoda za određivanje parametara prenosne funkcije servosistema i analiziran uticaj zanemarivanja električne vremenske konstante.

S obzirom na to da je ugrađen motor sa malom induktivnošću u praksi se na red dodaje induktivnost radi ograničenja brzine rasta struje rotora DC motora na primenjeni napon. Simuliran je sistem bez dodatne induktivnosti, kao i sa dve vrednosti induktivnosti $(150 \mu \mathrm{H}$ i $500 \mu \mathrm{H})$. Analiziran je uticaj promene induktivnosti, kao i opravdanost zanemarivanja električne vremenske konstante na odziv sistema odnosno podešavanje parametara regulatora.

Simulacija je urađena prvo za petlju po struji rotora, a sa tako podešenim strujnim regulatorom urađena je i simulacija petlje po ugaonoj brzini obrtne platforme. Podešen je regulator brzinske petlje i analiziran uticaj dodatne induktivnosti, kao i zanemarivanje električne vremenske konstante $u$ modelu servopogona.

Na osnovu rezultata simulacije može se zaključiti da je za projektovanje i podešavanje parametara digitalnog regulatora bolje koristiti model motora gde se ne zanemaruje električna vremenska konstanta, a pogotovo kada se dodaje redna induktivnost čija vrednost premašuje vrednost induktivnosti sa- 
mog motora. Takođe, bolje je koristiti brzinski regulator sa izmeštenim proporcionalnim dejstvom, pogotovo kada se koristi brzinski servosistem.

$\mathrm{Na}$ osnovu rezultata simulacije i ovako podešenih parametara regulatora moguće je pristupiti podešavanju realnog sistema, koristeći rezultate simulacije kao početne vrednosti za parametre realnog regulatora.

Ovakav put rada može se primeniti za proučavanje i eksperimentisanje, kao i poboljšanje sistema koji se ispituje. Takođe, ovakva simulacija se može primeniti pri radu na sličnim sistemima, jer štedi vreme i trud pri podešavanju parametara regulatora realnog sistema. Simulacijom se smanjuje mogućnost grešaka ili eventualnih akcidenata usled pogrešno proračunatih početnih vrednosti parametara za slučaj da se radi direktno na realnom sistemu.

\title{
Literatura
}

[1] Stojić, M., Kontinualni sitemi automatskog upravljanja, Naučna knjiga, Beograd, 1980.

[2] Stojić, M., Digitalni sistemi upravljanja, Naučna knjiga, Beograd, 1989.

[3] Maxon motor program, 2009, www.maxonmotor.com

[4] Jezdimirović, M., Dodić, N., „Određivanje momenta inercije obrtne platforme borbenog sredstva", Naučno-tehnički pregled, No. 10, Beograd, 1991.

[5] Viličić, A., Jezdimirović, M., „Digitalni servo sistem za upravljanje infracrvenim lokatorom", Vojnotehnički glasnik (Military Technical Courier), Vol. 57, No. 2, pp 5-15, ISSN 0042-8469, UDK 623+355/359, Beograd, 2009.

\section{SIMULATION OF ADDED INDUCTIVE COIL INFLUENCE ONTO THE DIGITAL SERVO SYSTEM WITH DC MOTOR}

\author{
FIELD: Electrical Engineering and Electronics (Automation and \\ Control) \\ Summary:
}

This paper describes a simulation of a real electrical servo drive with a digital equalizer. The whole system is simulated in the simulation toolkit of the LabView package. Real transfer functions are simulated (the transfer functions of the motor and the current and angular velocity gauges), as well as the nonlinearities of the motor and the gears. Clasical mathematical methods for modeling servosistems are used. The method for determining transfer function parameters is also used. The influence of neglecting the electrical time constant is analysed.

System description

A real electrical servo drive with the digital regulation for turret drive in traverse is simulated. Different values of added inductance are simulated and the equalizer parameters are matched so that the system has an acceptable response. 
Mathematical model of a servo system for modular turret drive in traverse

The characteristics of the used motor are given. All equations for the DC motor are also given as well as the transfer function. Based on the calculations and measurements, the exact parameters of the transfer functions are found. For each value of added inductance, the parameters of the transfer functions are found.

Simulation results

The simulation toolkit from the LabView software package has been used for the system simulation and the equalizer parameters for current and velocity feedback have been found. The parameters have been chosen so that the response of the simulated servo sistem has the required characteristics.

The results of this simulation are given graphically, through a series of graphs, taken from the simulation program, presenting the characteristic responses for such exitations.

\section{Conclusions}

A real electrical servo drive with a digital equalizer has been analyzed. The whole system (with all nonlinearities) is simulated in the simulation toolkit of the LabView package. Clasical mathematical methods for modeling servosistems are used.

The simulation has been done first for the inner (current) loop, and the equalizer parameters have been found. After tuning the inner loop, the outer loop is then simulated and its equalizer parameters tuned. The influence of different values of the added inductance onto the tuning equalizer parameters are analyzed.

A real design of such servo sistems may be performed on the basis of the simulation results and thus tuned equalizer parameters. The given parameters for equlizers may be used as a starting point in tuning real system parameters. This can save money and time in realisations in practice.

Key words: digital servo-system, digital regulator, control, inductive coil, automatic control.

Datum prijema članka: 23. 08. 2010.

Datum dostavljanja ispravki rukopisa: 10. 11. 2010.

Datum konačnog prihvatanja članka za objavljivanje: 12. 11. 2010. 